\title{
Selected Papers from the International Conference on Biopesticides 6 (ICOB6)
}

\author{
Kabkaew L. Sukontason, ${ }^{1}$ Mir S. Mulla, ${ }^{2}$ Siriwat Wongsiri, ${ }^{3}$ John T. Trumble, ${ }^{2}$ \\ and Jittawadee R. Murphy ${ }^{4}$
}

\author{
${ }^{1}$ Department of Parasitology, Faculty of Medicine, Chiang Mai University, Chiang Mai 50200, Thailand \\ ${ }^{2}$ Department of Entomology, University of California Riverside, CA 92521, USA \\ ${ }^{3}$ Graduate School, Maejo University, Chiang Mai 50290, Thailand \\ ${ }^{4}$ 18th MEDCOM (DS), Fort Shafter, Hawaii, HI 96858, USA
}

Correspondence should be addressed to Kabkaew L. Sukontason, klikitvo@gmail.com

Received 8 November 2012; Accepted 8 November 2012

Copyright ( $) 2012$ Kabkaew L. Sukontason et al. This is an open access article distributed under the Creative Commons Attribution License, which permits unrestricted use, distribution, and reproduction in any medium, provided the original work is properly cited.

There is a whole host of chemicals employed in plant protection practices around the world for pest and disease control. Some of the same groups of chemicals are also used for controlling pests and vectors of human diseases. With the advent of DDT some 7 decades ago, a variety of synthetic pesticides were discovered, designed, and evaluated for pesticidal activity. Compounds and moieties having different modes of action were studied and developed for the control of pests and diseases. In the realm of insecticides, the organochlorine insecticides generated great hope and yielded tremendous successes in the area of plant protection and management of some vector-borne diseases. The organochlorines were followed by even more powerful insecticides such as organophosphate, carbamate, and other groups of active agents. Although these insecticides provided excellent control of major pests of crops and humans, they posed considerable environmental problems, such as adverse effects on fish and wildlife, high toxicity to mammals, biomagnification, persistence in water, soil, and food crops. Additionally, the emergence of resistance in target species appears over large areas of the globe, and many of the newly developed control agents became obsolete in a matter of a few years. Responding to these concerns, experts and stake holders in plant protection and disease vector control programs shifted their research focus to the discovery, development, and use of alternative and envirofriendly agents. Thus a new era for the development and practical use of natural and biorational products and biopesticides dawned. Biopesticides include not only plant based bioactive agents but also other natural products of various origins. Since 1995, we have been organizing and holding regional international conferences on the broad subject of biopesticides, where the last one, ICOB6, was held in Chiang Mai, Thailand.

This special issue addresses the role of biopesticides in pest management. The themes include biorational agents, plant-based products, natural products, microbial control agents, antagonistic bacteria, and fungi. From 14 submissions, 6 papers were selected and are published in this special issue, of which 5 were research papers and 1 was a review article. Each paper was reviewed by at least two reviewers and revised according to review comments.

In Intirach et al.'s paper, the authors presented the larvicidal efficacy of essential oils of five plants-Piper sarmentosum, Foeniculum vulgare, Curcuma longa, Myristica fragrans, and Zanthoxylum piperitum-against laboratorycolonized Anopheles cracens mosquitoes, showing 95\%$100 \%$ larval mortality at concentration of $100 \mathrm{ppm}$. The strongest larvicidal potential was established from $P$. sarmentosum, followed by $F$. vulgare, C. longa, M. fragrans, and $Z$. piperitum, based on the $\mathrm{LC}_{50}$ values. The authors also analyzed the chemical compositions by gas chromatography coupled to mass spectrometry, demonstrating the main component in the oil derived from such plants. Binary mixtures between $P$. sarmentosum, the most effective oil, and the others were proved to be highly efficacious, indicating 
synergistic activity. This paper offers some interesting thoughts of the synergistic effects from mixed formulations of different essential oils, which may be helpful in developing effective, economical, and ecofriendly larvicides, as favorable alternatives for mosquito management.

In this special issue, there are two papers studying the fungi or plant extracts against agronomical mites. Bussaman et al.'s paper presented the efficacy of 23 rhizome and leaf extracts against adult female of the Mushroom mite, Luciaphorus sp., a destructive pest of several mushroom species. The rhizome extracts derived from Curcuma xanthorrhiza and Zingiber montanum revealed strong acaricidal activities, followed by Curcuma longa, Zingiber zerumbet, Kaempferia parviflor and Zingiber officinale. In addition, the leaf extracts of Ocimum sanctum and Melissa officinalis also caused strong mortality. Such information provided a great potential for future development as natural acaricides for controlling Luciaphorus sp. Another paper is by Erdogan et al.'s, reporting the efficacy of biopesticides extracted from five different plants (i.e., Allium sativum, Rhododendron luteum, Helichrysum arenarium, Veratrum album, and Tanacetum parthenium) against the two-spotted mite, Tetranychus urticae, an economic pest causing serious damage to vegetables, flowers, and fruit crops worldwide. The bioassays demonstrated not only the high mortality but also lower numbers of eggs' production.

Research on the fungicide activity of some crude plant extracts or bacteria has also been published. Bussaman et al. evaluated in vitro the efficacy of 14 crude leaf extracts against Colletotrichum gloeosporioides - a fungus that causes anthracnose disease in tropical fruits. The crude leaf extracts from Piper sarmentosum, using the ethanol, methanol, and chloroform as solvents, showed high antifungal activities by inhibiting both mycelium growth and spore germination. Such information provides the potential of these new natural fungicides for management of anthracnose disease. Another paper on fungicide activity of bacteria is provided by Loliam's et al. The authors demonstrated the results of using antagonistic actinomycetes, Streptomyces rubrolavendulae S4, against Phytophthora infestans, the pathogenic fungi causing the seedling damping off disease in several economic crops in Thailand. This bacterium was proven to induce most effective growth inhibition of fungi tested on potato dextrose agar. In $P$. infestans contaminated peat moss, the survival of tomato and chili seedling was significantly increased for $S$. rubrolavendulae $\mathrm{S} 4$ treatment. In addition, S. rubrolavendulae S4 showed high efficiency equivalent to fungicide, metalaxyl with no significant difference. The authors propose that this bacterium can prevent the tomato and chili seedling damping off disease in economic plant nurseries.

Only one review article is published in this special issue by Rajashekar et al., focusing on the current state of the botanical insecticides as grain protectants and their mode of action, based on numerous references. On the basis of physiological activities on insects, the plant components has been conventionally classified into 6 groups, namely, repellents, feeding deterrents/antifeedants, toxicants, growth retardants, chemosterilants, and attractants. Focus on the activity of toxicants and grain protectants using essential oils, extracts, and their constituent has sharpened since the 1980s. Some insecticidal active principles of plants are listed. The botanical insecticides that have primarily been used and are commercially available include ryania, rotenone, pyrethrin, nicotine, azadirachtin, and sabadilla. This review proposed that it is possible to develop methods for grain protectants with reduced use of synthetic chemical insecticides.

These papers represent an exciting, insightful observation into the biopesticides point of view. However, research efforts should focus not only on their efficacy but also on mammalian toxicity, mode of action in insects, seed germination, effect on nutritional quality, seedling growth, and stability of the compound. The insecticides of plant origin could be exploited for the development of novel molecules with highly precise targets for sustainable insect pest management in stored grain. We hope that this special issue would attract a major attention of the peers. We would like to express our appreciation to all the authors, reviewers, and the Editor-in-Chief, Dr. Kabkaew L. Sukontason, for great support that made this special issue possible.

Kabkaew L. Sukontason Mir S. Mulla Siriwat Wongsiri John T. Trumble Jittawadee R. Murphy 

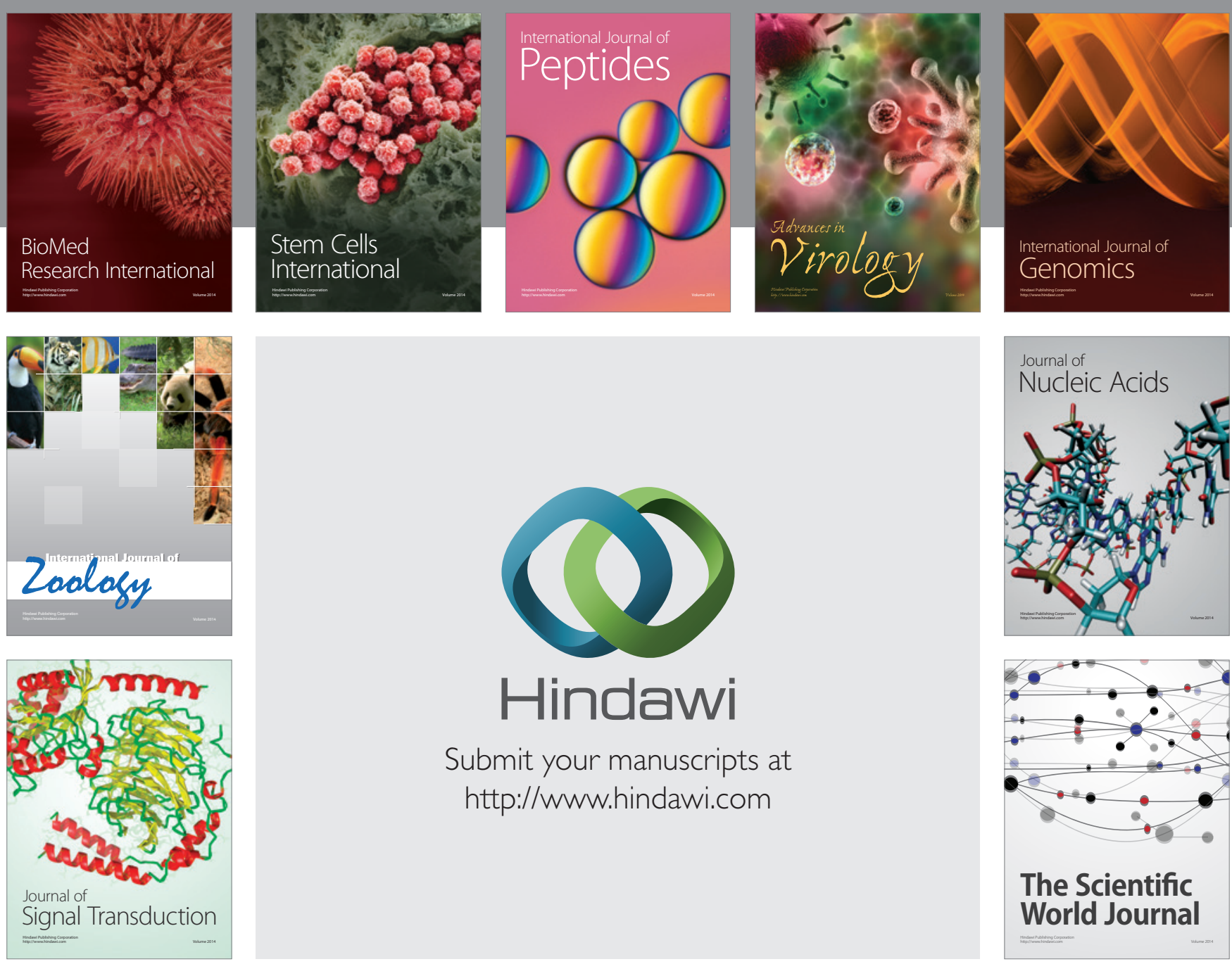

Submit your manuscripts at

http://www.hindawi.com
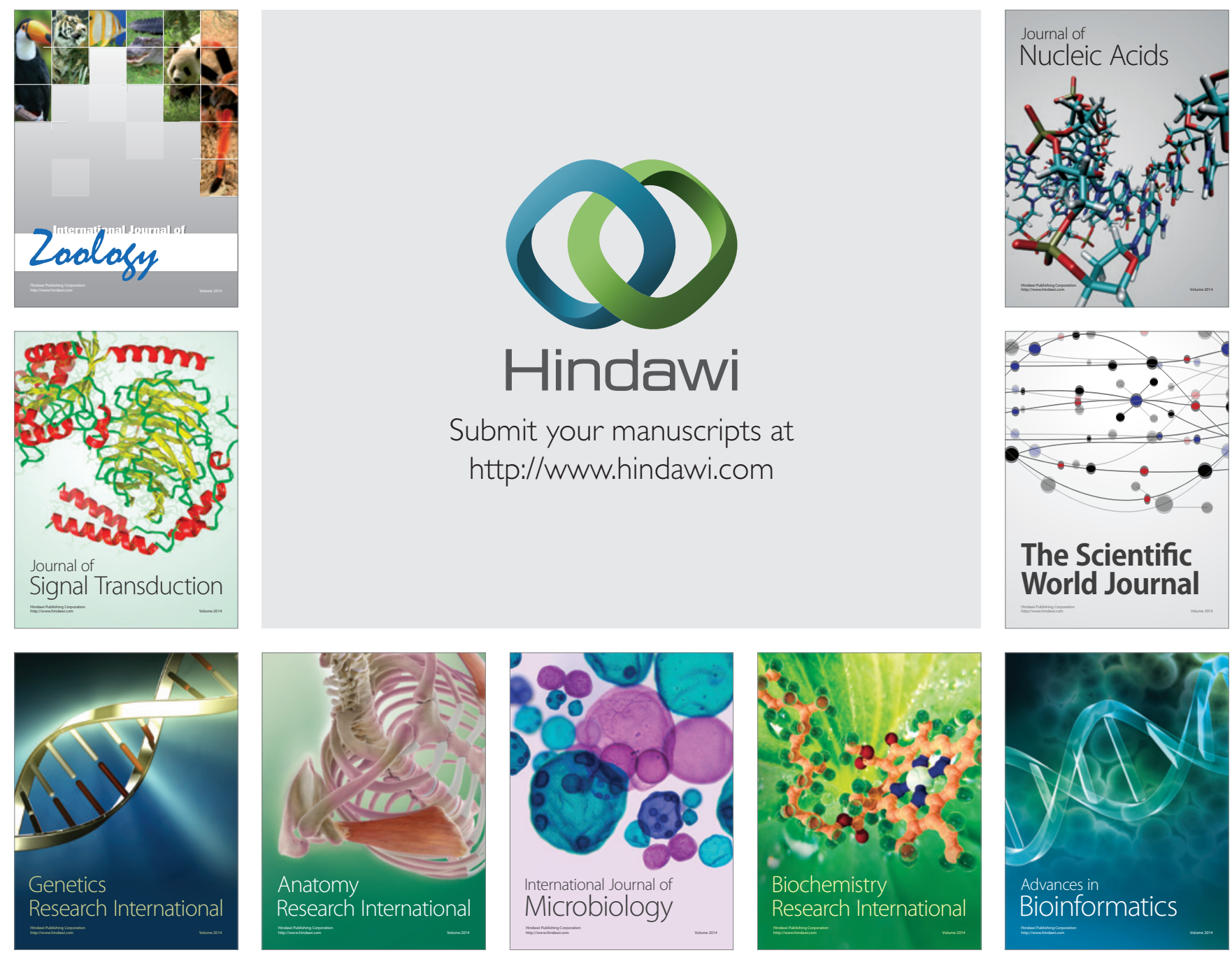

The Scientific World Journal
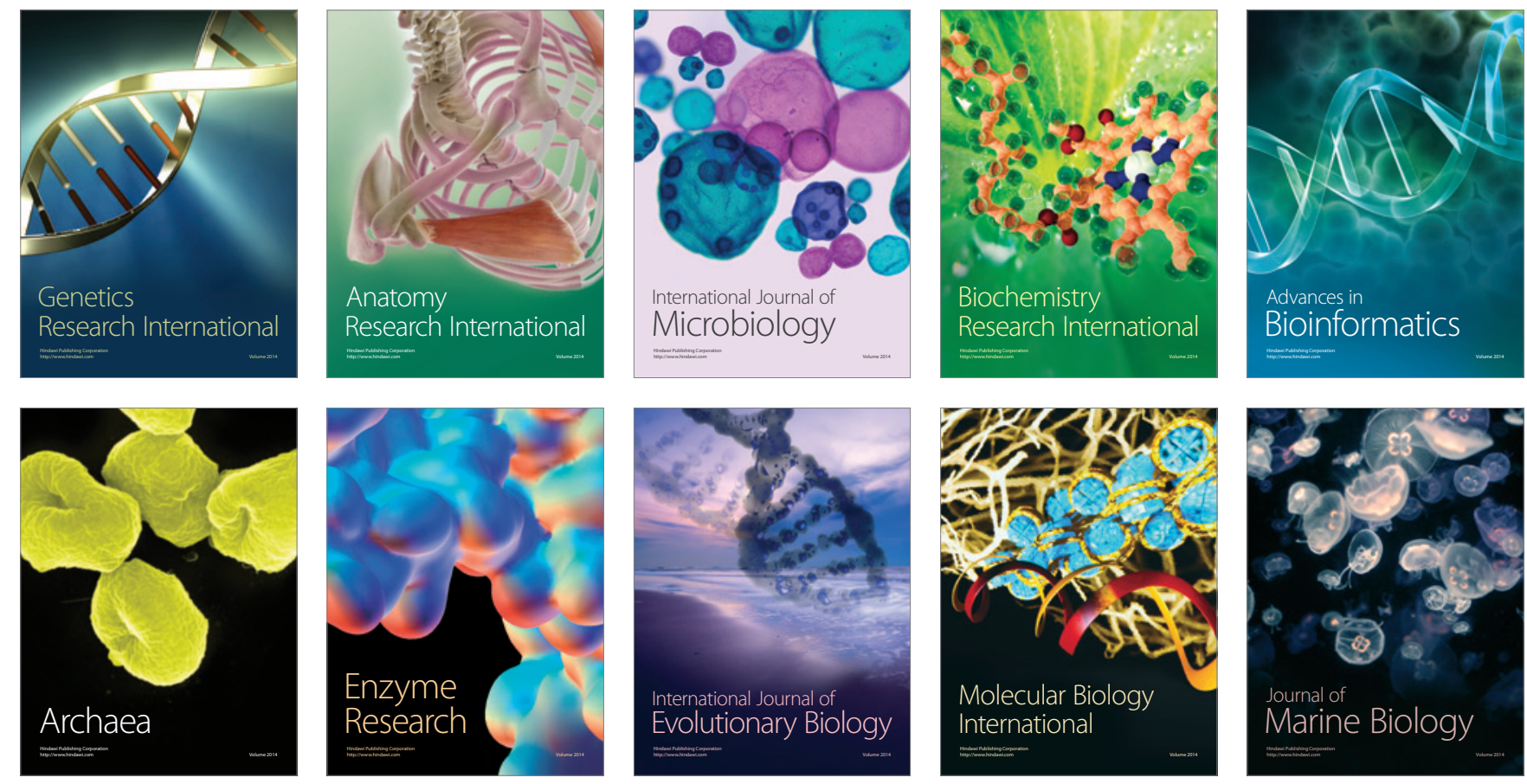